\title{
Gravitactic orientation of Euglena gracilis-a sensitive endpoint for ecotoxicological assessment of water pollutants
}

\author{
Azizullah Azizullah ${ }^{1 *}$, Waheed Murad ${ }^{1}$, Muhammad Adnan ${ }^{1}$, Waheed Ullah ${ }^{2}$ and Donat-Peter Häder ${ }^{3}$ \\ 1 Department of Botany, Kohat University of Science and Technology, Kohat, Pakistan \\ 2 Department of Biotechnology and Genetic Engineering, Kohat University of Science and Technology, Kohat, Pakistan \\ ${ }^{3}$ Department of Biology, University of Erlangen, Erlangen, Germany
}

\section{Edited by:}

Abdel-Tawab H. Mossa, National

Research Centre, Egypt

Reviewed by:

Abdel-Tawab H. Mossa, National

Research Centre, Egypt

Peter R. Richter,

Friedrich-Alexander-University,

Germany

*Correspondence:

Azizullah Azizullah, Department of

Botany, Kohat University of Science and Technology, 26000 Kohat,

Pakistan

e-mail: azizswabi@hotmail.com
Pollution of aquatic environments with natural and anthropogenically produced substances is one of the major environmental problems of the world. In many countries the decreasing quantity of water coupled with its increasing usage in multiple sectors has adversely affected water quality and caused problems of water pollution. Polluted water has been a main cause of adverse effects on plants, animals and humans throughout the world. Physicochemical analysis of water, which is a common method used for quality assessment of water, alone may not be enough as it cannot evaluate the impact on living organisms. Therefore, bioassessment of water and wastewater quality is considered to be essential to reflect the ultimate effects on living organisms. Many organisms like bacteria, algae, fish, invertebrates and protozoan are used as bioassay organisms for assessment of water quality. This review article elucidates the use of Euglena gracilis, a freshwater motile flagellate of the phylum Euglenophyta, as a suitable organism in ecotoxicological studies with special emphasis on its gravitactic orientation as a sensitive end point in ecotoxicological assessment of water pollutants.

Keywords: bioassessment, ECOTOX, ecotoxicology, Euglena gracilis, gravitactic orientation, water pollution

\section{INTRODUCTION}

About $70 \%$ of the earth surface is covered by water, of which less than $3 \%$ is fresh water and the remaining is saline. Due to factors like rapid increase in population, urbanization, industrialization and huge consumption of water in industry and agriculture, an immense stress on the quantity and quality of the available freshwater has been developed. In many countries the increasing usage of water in multiple sectors coupled with decreasing availability has adversely affected the quality of water and resulted in problems of severe water pollution. Polluted water has been among the main causes of various health problems in humans throughout the world. An estimate reveals that about 2.3 billion people in the world are suffering from diseases that are linked to water contamination (UNESCO, 2003). Every year, more than 2.2 million people across the developing world die from diseases related to inadequate sanitation and unclean water (WHO and UNISEF, 2000). In addition to health problems in humans, contaminated water has been reported as a cause of the death of aquatic organisms and livestock as well as has adverse effects on biodiversity and agricultural production (Nasrullah et al., 2006).

For the evaluation of water and wastewater quality, analytical methods are usually applied to evaluate physicochemical characteristics of water samples; however, these are expensive, may not cover all the toxic substances present in a sample and do not reflect the adverse effects on biota (Streb et al., 2002). In many countries, particularly in the developed world, wastewater treatment and cleaning is obligatory before it is discharged.
But even after treatment, many toxic substances may still be present in wastewater in small quantities, which can have possible adverse affects on living organisms. However, these effects on living organisms cannot be assessed by chemical analysis techniques (Danilov and Ekelund, 2000). Therefore, assessment of water and wastewater quality using bioassays is important to reflect the ultimate effects on living organisms. The main objective of this review is to describe Euglena gracilis as an ideal organism in ecotoxicological studies with special emphasis on its gravitactic orientation as a sensitive end point parameter.

\section{BIOASSESSMENT OF WATER QUALITY}

Many bioassays based on different organisms like bacteria, algae, fish, invertebrates and protozoa are being used for the assessment of water quality. One of the commonly used bioassays is that based on the changes in the bioluminescence of the bacterium Vibrio fischeri upon exposure to toxic substances. Due to the short response time, the bioluminescence tests have been widely used for toxicity assessment of various toxic substances in fresh and marine waters (Boyd et al., 2001; Vetrova et al., 2002; Wang et al., 2002). Standard test devices based on the luminescence of this bacterium like MICROTOX (Strategic Diagnostics Inc., Newark, USA) and LUMIStox (Dr. Lange, Berlin, Germany) have been developed for a fast analysis of water samples (Kaiser, 1998; Streb et al., 2002).

Crustaceans such as Daphnia and Ceriodaphnia are also being widely used as biotest organisms. Toxicity assessment with these 
organisms is mostly based on the immobilization of the organisms upon exposure to the test substance but the survival is also used as an end point. For example, Kline et al. (1989) performed the immobility tests with three species of cladocerans, namely Daphnia pulex, Daphnia magna, and Ceriodaphnia dubia to evaluate the toxicity of the pesticide triphenyltin hydroxide. The immobility tests with Daphna magna and Ceriodaphnia cf. dubia were also applied for acute toxicity assessment of various detergents and detergent components (Warne and Schifko, 1999; Pettersson et al., 2000). Similarly, Chen and Liu (2008) evaluated the toxicity of the fungicide metalaxyl using $48 \mathrm{~h}$ mortality tests with Daphnia magna.

Fish are also known to be very vulnerable to pollutants and are used as sensitive test organisms in toxicity assessment of chemicals in aquatic environments. Behavioral responses of fish like swimming performance have commonly been used as end points in evaluating the toxic effect of toxicants. A video analysis system has been designed which investigates the stress or toxicity by recording changes in the behavioral parameters of fish like velocity, percent movement, total distance traveled, space utilization, angular change and fractal dimension (Kane et al., 2004). Bioassays based on the electric organ discharges (EOD) of fish species like Apteronotus albifrons, Gnathonemus petersi and Gnathonemas tamandua have also been developed (Geller, 1984; Lewis et al., 1995; Thomas et al., 1996).

Higher plants are also applied in the assessment of toxic substances. A common bioassay used for assessing pollutants in aquatic environment involving higher plants is that with duckweed, a group of flowering floating plants that belong to the family lemnaceae (Wang, 1990). Due to characteristics like small size, widespread occurrence, fast growth and high sensitivity to toxic substances, duckweed is accepted as an ideal organism for bioassessment in aquatic environments (Wang, 1990). Various active pollutants of aquatic environments like heavy metals, phenolic compounds and pesticides have been assessed for their toxicity potential using duckweed species (Wang, 1990; Mohan and Hosetti, 1997; Hou et al., 2007; Paczkowska et al., 2007).

Among the various bioassay organisms used in aquatic ecotoxicology, algae are considered to be more suitable organisms as they have higher sensitivity to aquatic pollutants and are the abundantly occurring organisms in aquatic environments (Danilov and Ekelund, 2000; Ahmed and Häder, 2010a). An advantage of algal biotests is that they are easy to perform and allow observing multiple generations. Algal bioassays also help avoiding the use of experimental animals which is desirable for economical and ethical reasons (Millán de Kuhn et al., 2006). Diverse species of algae belonging to different groups, e.g., Chlorella, Laminaria, Raphidocelis, Scenedesmus, and Selenastrum have been used for bioassessment of fresh and marine water pollutants (Pybus, 1973; Christensen et al., 1979; Anton et al., 1993; Ma et al., 2002; Pavlic et al., 2005). Different algal parameters like cell number, fresh or dry weight, protein and nucleic acid contents, chlorophyll fluorescence, $\mathrm{CO}_{2}$ fixation, ATP production, morphology or vital stainability are being used as endpoints in ecotoxicology (Rai et al., 1994).

\section{Euglena gracilis-AS A BIOASSAY ORGANISM}

E. gracilis is a unicellular motile flagellate of the phylum Euglenophyta and is found in many freshwater aquatic habitats, especially shallow eutrophic ponds (Tahedl and Häder, 2001). Due to its rapid and sensitive response to various toxic substances like heavy metals and inorganic and organic compounds, E. gracilis has been among the widely used organisms in ecotoxicological studies. Numerous behavioral, biochemical, morphological and physiological parameters of Euglena are being used as end points in biomonitoring of water pollutants. For example, cell growth in Euglena has been used in numerous studies to evaluate the effects of different substances (Gajdosova and Reichrtova, 1996; Aronsson and Ekelund, 2005). Its motility, orientation and morphological parameters like percent motility, swimming velocity, upward swimming and cell shape have been widely used for assessing the toxicity of water pollutants of both organic and inorganic nature including wastewaters (Tahedl and Häder, 1999; Pettersson and Ekelund, 2006; Azizullah et al., 2013). Photosynthetic efficiency and composition of photosynthetic pigments in this flagellate were found to be sensitive to different chemicals and have been used as end points in assessing the impact of toxic chemicals (Nass and Ben Shaul, 1973; Ahmed, 2010; Azizullah et al., 2012).

\section{GRAVITAXIS IN E. gracilis-A SENSITIVE END POINT IN ECOTOXICITY ASSESSMENT}

E. gracilis has a flagellum inserted at the front end which is used as a locomotory organ (a second but rudimentary and non-functional small flagellum is also present but it does not protrude out of the frontal invagination) (Häder, 1987; Tahedl and Häder, 1999). E. gracilis uses light and gravity as external clues for orienting itself in the water to reach a region in the water column optimal for reproduction and growth (Häder, 1987; Richter et al., 2003). Both gravitaxis and phototaxis in Euglena are based on active physiological mechanisms (Kamphuis, 1999; Richter et al., 2001), and have been found to be impaired by external stressors such as heavy metals, organic and inorganic pollutants, increased salinity, and ultraviolet radiation (Tahedl and Häder, 1999; Richter et al., 2003). Various investigations led to the conclusion that the difference in density between the cell body and the surrounding medium is an important factor in the gravitactic orientation of Euglena (Lebert et al., 1999). Since the density of the cell body is higher than the surrounding medium, it causes a downward sedimentation of the cell contents which stretches the lower membrane by exerting a pressure on it. This stretching results in the activation of mechano-sensitive ion channels in the cell membrane and ultimately changes the membrane potential which triggers a reorientation of the flagellar movement (Lebert et al., 1999). The application of low concentrations of mechanosensitive ion channel inhibitors, such as gadolinium, strongly impaired the gravitactic orientation which revealed the involvement of mechano-sensitive ion channels in gravitactic orientation (Franco et al., 1991). The pollutants present in a water sample affect these mechano-sensitive ion channels and thus cause impairment of the gravitactic orientation in Euglena cells (Tahedl and Häder, 1999). 
With the development of the automatic bioassay device ECOTOX (Tahedl and Häder, 1999, 2001), which uses motility and orientation parameters of Euglena as end points, gravitactic orientation in this flagellate has widely been accepted and applied in ecotoxicological assessment of aquatic pollutants of diverse nature. For example, it was successfully applied in the toxicity assessment of heavy metals (Ahmed, 2010), organic pollutants (Tahedl and Häder, 1999, 2001), fertilizers (Azizullah et al., 2012), pesticides (Pettersson and Ekelund, 2006; Azizullah et al., 2011a,b,c,d), detergents (Azizullah et al., 2011a,b,c,d) and wastewater (Ahmed, 2010; Azizullah et al., 2013). In short-term tests, the gravitactic orientation in E. gracilis has been reported to be more sensitive toward wastewaters and many other pollutants as compared to other motility parameters of the organism (Tahedl and Häder, 1999; Ahmed, 2010; Azizullah et al., 2011a,b,c,d, 2012). The presence of mechano-sensitive ion channels in the cell membrane of Euglena and their role as gravireceptors (Häder et al., 2009) has been regarded as a probable reason for the higher sensitivity of gravitaxis in Euglena to aquatic pollutants (Ahmed and Häder, 2010b). Previous studies also revealed that motility and orientation in E. gracilis were more sensitive than photosynthesis (measured by chlorophyll fluorescence) to different pollutants (Ahmed, 2010; Azizullah et al., 2011a,b,c,d, 2013). Based on the assessment of many wastewater samples collected from different industries by our group, we have concluded that precision of gravitactic orientation in E. gracilis is the most sensitive parameter toward wastewater toxicity during short-time tests (immediately after exposure) (Azizullah et al., 2011b, 2012, 2013). These parameters were also found to be more sensitive than other common biotests such as algal growth test, Daphnia motility test, fish mortality test, and bacterial bioluminescence test (MICROTOX) to wastewater toxicity from different industries (Ahmed and Häder, 2011).

Gravitactic orientation, in combination with other motility parameters of Euglena, makes ECOTOX an ideal system for ecotoxicological assessments in aquatic environments. In comparison to other commonly used biotests, low costs and short time for measurement are the main advantages of ECOTOX. Depending upon setting of the software, 6-10 min are needed for one complete measurement of a sample along with the corresponding control. Automated measurement and data analysis and the usage of multiple parameters as end points are other advantages of ECOTOX (Azizullah et al., 2011b).

\section{CONCLUSIONS}

Pollution of aquatic environments from natural and anthropogenic sources is one of the major environmental problems of the world. Physicochemical analysis of water alone may not be enough as it does not reflect the adverse effects on living organisms. The involvement of bioassays is necessary in pollution monitoring of aquatic environments. E. gracilis is an ideal organism for use in ecotoxicological studies with its various physiological, biochemical and behavioral parameters used as end points. The automatic biotest ECOTOX is a value tool in pollution monitoring. Among its various end point parameters, gravitactic orientation of Euglena is recommended as the most sensitive end point in short-term (immediately upon exposure) assessment of aquatic pollutants.

\section{REFERENCES}

Ahmed, H. (2010). Biomonitoring of Aquatic Ecosystems. Ph.D dissertation, Friedrich-Alexander University, Erlangen; Nürenberg.

Ahmed, H., and Häder, D.-P. (2010a). A fast algal bioassay for assessment of copper toxicity in water using Euglena gracilis. J. Appl. Phycol. 22, 785-792. doi: 10.1007/s10811-010-9520-Z

Ahmed, H., and Häder, D.-P. (2010b). Rapid ecotoxicological bioassay of nickel and cadmium using motility and photosynthetic parameters of Euglena gracilis. Environ. Exp. Bot. 69, 68-75. doi: 10.1016/j.envexpbot.2010.02.009

Ahmed, H., and Häder, D.-P. (2011). Monitoring of waste water samples using the ECOTOX biosystem and the flagellate alga Euglena gracilis. Water Air Soil Pollut. 216, 547-560. doi: 10.1007/s11270-010-0552-4

Anton, F. A., Laborda, E., Laborda, P., and Ramos, E. (1993). Carbofuran acute toxicity to freshwater algae and fish. Bull. Environ. Contam. Toxicol. 50, 400-406. doi: 10.1007/BF00197200

Aronsson, K. A., and Ekelund, N. G. A. (2005). Effects on motile factors and cell growth of Euglena gracilis after exposure to wood ash solution; assessment of toxicity, nutrient availability and pH-dependency. Water Air Soil Pollut. 162, 353-368. doi: 10.1007/s11270-005-7250-7

Azizullah, A., Jamil, M., Richter, P., and Häder, D.-P. (2013). Fast bioassessment of waste- and surface- water quality using freshwater flagellate Euglena gracilis - a case study from Pakistan. J. Appl. Phycol. doi: 10.1007/s10811-013-0100-x (in press).

Azizullah, A., Nasir, A., Richter, P., Lebert, M., and Häder, D.-P. (2011a). Evaluation of the adverse effects of two commonly used fertilizers, DAP and urea, on motility and orientation of the green flagellate Euglena gracilis. Environ. Exp. Bot. 74, 140-150. doi: 10.1016/j.envexpbot.2011.05.011

Azizullah, A., Richter, P., and Häder, D.-P. (2011b). Ecotoxicological evaluation of wastewater samples from Gadoon Amazai Industrial Estate (GAIE), Swabi, Pakistan. Int. J. Environ. Sci. 1, 959-976

Azizullah, A., Richter, P., and Häder, D.-P. (2011c). Comparative toxicity of the pesticides carbofuran and malathion to the freshwater flagellate Euglena gracilis. Ecotoxicology 20, 1442-1454. doi: 10.1007/s10646-011-0701-6

Azizullah, A., Richter, P., and Häder, D.-P. (2011d). Toxicity assessment of a common laundry detergent using the freshwater flagellate Euglena gracilis. Chemosphere 84, 1392-1400. doi: 10.1016/j.chemosphere.2011.04.068

Azizullah, A., Richter, P., and Häder, D.-P. (2012). Sensitivity of various parameters in Euglena gracilis to short-term exposure to industrial wastewaters. J. Appl. Phycol. 24, 187-200. doi: 10.1007/s10811-011-9667-2

Boyd, M. E., Killham, K., and Meharg, A. A. (2001). Toxicity of mono-, di- and tri-chlorophenols to lux marked terrestrial bacteria, Burkholderia species Rasc c2 and Pseudomonas fluorescens. Chemosphere 43, 157-166. doi: 10.1016/S00456535(00)00266-6

Chen, S., and Liu, W. (2008). Toxicity of chiral pesticide Rac-Metalaxyl and $R$ Metalaxyl to Daphnia magna. Bull. Environ. Contam. Toxicol. 81, 531-534. doi: 10.1007/s00128-008-9567-6

Christensen, E. R., Scherfig, J., and Dixon, P. S. (1979). Effects of manganese, copper and lead on Selenastrum capricornutum and Chlorella stigmatophora. Water Res. 13, 79-92. doi: 10.1016/0043-1354(79)90258-6

Danilov, R., and Ekelund, N. (2000). Applicability of growth rate, cell shape, and motility of Euglena gracilis as physiological parameters for bioassessment at lower concentrations of toxic substances: an experimental approach. Environ. Toxicol. 16, 78-83. doi: 10.1002/1522-7278(2001)16:1<78::AIDTOX90>3.3.CO;2-0

Franco, A. Jr., Winegar, B. D., and Lansman, J. B. (1991). Open channel block by gadolinium ion of the stretch-inactivated ion channel in $m d x$ myotubes. Biochem. J. 59, 1164-1170.

Gajdosova, J., and Reichrtova, E. (1996). Different growth response of Euglena gracilis to $\mathrm{Hg}, \mathrm{Cd}, \mathrm{Cr}$ and Ni compounds. Fresenius J. Anal. Chem. 354, 641-642.

Geller, W. (1984). A toxicity warning monitor using the weakly electric fish, Gnathonemus petersi. Water Res. 18, 1285-1290. doi: 10.1016/00431354(84)90034-4

Häder, D.-P. (1987). Polarotaxis, gravitaxis and vertical phototaxis in the green flagellate, Euglena gracilis. Arch. Microbiol. 147, 179-183. doi: 10.1007/BF00415281

Häder, D.-P., Richter, P., Schuster, M., Daiker, V., and Lebert, M. (2009). Molecular analysis of the graviperception signal transduction in the flagellate Euglena 
gracilis: involvement of a transient receptor potential-like channel and a calmodulin. Adv. Space Res. 43, 1179-1184. doi: 10.1016/j.asr.2009.01.029

Hou, W., Chen, X., Song, G., Wang, Q., and Chang, C. C. (2007). Effects of copper and cadmium on heavy metal polluted water body restoration by duckweed (Lemna minor). Plant Physiol. Biochem. 45, 62-69. doi: 10.1016/j.plaphy.2006.12.005

Kaiser, K. L. E. (1998). Correlations of Vibrio fischeri bacteria test data with bioassay data for other organisms. Environ. Health Perspect. 106, 583-591.

Kamphuis, A. (1999). Digitale Pfadanalyse am Beispiel der Schwerkraftausrichtung von Euglena gracilis in Flachküvetten (in German). Bonn: Rheinische-FriedrichWilhelms-Universität Bonn.

Kane, A. S., Salierno, J. D., Gipson, G. T., Molteno, T. C. A., and Hunter, C. (2004). A video-based movement analysis system to quantify behavioral stress responses of fish. Water Res. 38, 3993-4001. doi: 10.1016/j.watres.2004.06.028

Kline, E. R., Jarvinen, A. W., and Knuth, M. L. (1989). Acute toxicity of triphenyltin hydroxide to three cladoceran species. Environ. Pollut. 56, 11-17. doi: 10.1016/0269-7491(89)90117-6

Lebert, M., Porst, M., Richter, P., and Häder, D.-P. (1999). Physical characterization of gravitaxis in Euglena gracilis. J. Plant Physiol. 155, 338-343. doi: 10.1016/S0176-1617(99)80114-X

Lewis, J. W., Kay, A. N., and Hanna, N. S. (1995). Responses of electric fish (family mormyridae) to inorganic nutrients and triubinryltin oxide. Chemosphere 31, 3753-3769. doi: 10.1016/0045-6535(95)00250-C

Ma, J., Zheng, R., Xu, L., and Wang, S. (2002). Differential sensitivity of two green algae, Scenedesmus obliqnus and Chlorella pyrenoidosa, to 12 pesticides. Ecotoxicol. Environ. Safety 52, 57-61. doi: 10.1006/eesa.2002.2146

Millán de Kuhn, R., Streb, C., Breiter, R., Richter, P., Neeße, T., and Häder, D.-P. (2006). Screening for unicellular algae as possible bioassay organisms for monitoring marine water samples. Water Res. 40, 2695-2703. doi: 10.1016/j.watres.2006.04.045

Mohan, B. S., and Hosetti, B. B. (1997). Potential phytotoxicity of lead and cadmium to Lemna minor grown in sewage stabilization ponds. Environ. Pollut. 98, 233-238. doi: 10.1016/S0269-7491(97)00125-5

Nasrullah, Naz, R., Bibi, H., Iqbal, M., and Durrani, M.I. (2006). Pollution load in industrial effluent and ground water of Gadoon Amazai Induatrial Estate (GAIE) Swabi, NWFP. J. Agric. Biol. Sci. 1, 18-24.

Nass, M. M., and Ben Shaul, Y. (1973). Effects of ethidium bromide on growth, chlorophyll synthesis, ultrastructure and mitochondrial DNA in green and bleached mutant, Euglena gracilis. J. Cell Sci. 13, 567-590.

Paczkowska, M., Kozlowska, M., and Golinski, P. (2007). Oxidative stress enzyme activity in Lemna minor L. exposed to cadmium and lead. Acta Biol. Cracov. Ser. Bot. 49, 33-37.

Pavlic, Z., Vidakovic-Cifrek, Z., and Puntaric, D. (2005). Toxicity of surfactants to green microalgae Pseudokirchneriella subcapitata and Scenedesmus subspicatus and to marine diatoms Phaeodactylum tricornutum and Skeletonema costatum. Chemosphere 61, 1061-1068. doi: 10.1016/j.chemosphere.2005.03.051

Pettersson, A., Adamsson, M., and Dave, G. (2000). Toxicity and detoxification of Swedish detergents and softener products. Chemosphere 41, 1611-1620. doi: 10.1016/S0045-6535(00)00035-7

Pettersson, M., and Ekelund, N. G. A. (2006). Effects of the herbicides Roundup and Avans on Euglena gracilis. Arch. Environ. Contam. Toxicol. 50, 175-181. doi: 10.1007/s00244-004-0042-z

Pybus, C. (1973). Effects of anionic detergent on the growth of Laminaria. Mar. Pollut. Bull. 4, 73-77. doi: 10.1016/0025-326X(73)90242-7

Rai, L. C., Gaur, J. P., and Soeder, C. J. (1994). Algae and Water Pollution. Stuttgart: E. Schweizerbart'sche Verlagsbuchhandlung.
Richter, P., Börnig, A., Streb, C., Ntefidou, M., Lebert, M., and Häder, D.-P. (2003). Effects of increased salinity on gravitaxis in Euglena gracilis. J. Plant Physiol. 160, 651-656. doi: 10.1078/0176-1617-00828

Richter, P., Lebert, M., Korn, R., and Häder, D.-P. (2001). Possible involvement of the membrane potential in the gravitactic orientation of Euglena gracilis. J. Plant Physiol. 158, 35-39. doi: 10.1078/01761617-00194

Streb, C., Richter, P., Sakashita, T., and Häder, D.-P. (2002). The use of bioassays for studying toxicology in ecosystems. Curr. Top. Plant Biol. 3, 131-142.

Tahedl, H., and Häder, D.-P. (1999). Fast examination of water quality using the automatic biotest ECOTOX based on the movement behavior of a freshwater flagellate. Water Res. 33, 426-432. doi: 10.1016/S0043-1354(98)00224-3

Tahedl, H., and Häder, D.-P. (2001). Automated biomonitoring using real time movement analysis of Euglena gracilis. Ecotoxicol. Environ. Safety 48, 161-169. doi: 10.1006/eesa.2000.2004

Thomas, M., Florion, A., ChrӨtien, D., and Terver, D. (1996). Real-time biomonitoring of water contamination by cyanide based on analysis of the continuous electric signal emitted by a tropical fish: Apteronotus albifrons. Water Res. 30, 3083-3091. doi: 10.1016/S0043-1354(96)00190-X

UNESCO. (2003). Water for People Water for Life. The United Nations World Water Development Report. Paris; New York, NY; Oxford: United Nations Educational, Scientific and Cultural Organization (UNESCO), and Berghahn Books.

Vetrova, E., Kratasyuk, V., and Kudryasheva, N. (2002). Bioluminescence characteristics of Lake Shira water. Aquat. Ecol. 36, 309-315. doi: 10.1023/A:1015638909971

Wang, C., Yediler, A., Lienert, D., Wang, Z., and Kettrup, A. (2002). Toxicity evaluation of reactive dyestuffs, auxiliaries and selected effluents in textile finishing industry to luminescent bacteria Vibrio fischeri. Chemosphere 46, 339-344. doi: 10.1016/S0045-6535(01)00086-8

Wang, W. (1990). Literature review on duckweed toxicity testing. Environ. Res. 52, 7-22. doi: 10.1016/S0013-9351(05)80147-1

Warne, M. S. J., and Schifko, A. D. (1999). Toxicity of laundry detergent components to a freshwater cladoceran and their contribution to detergent toxicity. Ecotoxicol. Environ. Safety 44, 196-206. doi: 10.1006/eesa.1999.1824

WHO, and UNISEF. (2000). Global Water Supply and Sanitation Assessment 2000 Report. Available online at: http://www.who.int/watersanitationhealth/ monitoring/jmp2000.pdf, World Health Organization and United Nations Children's Fund, USA.

Conflict of Interest Statement: The authors declare that the research was conducted in the absence of any commercial or financial relationships that could be construed as a potential conflict of interest.

Received: 05 November 2013; paper pending published: 05 December 2013; accepted: 06 December 2013; published online: 24 December 2013.

Citation: Azizullah A, Murad W, Adnan M, Ullah W and Häder D-P (2013) Gravitactic orientation of Euglena gracilis - a sensitive endpoint for ecotoxicological assessment of water pollutants. Front. Environ. Sci. 1:4. doi: 10.3389/fenvs.2013.00004 This article was submitted to Environmental Toxicology, a section of the journal Frontiers in Environmental Science.

Copyright (c) 2013 Azizullah, Murad, Adnan, Ullah and Häder. This is an openaccess article distributed under the terms of the Creative Commons Attribution License (CC BY). The use, distribution or reproduction in other forums is permitted, provided the original author(s) or licensor are credited and that the original publication in this journal is cited, in accordance with accepted academic practice. No use, distribution or reproduction is permitted which does not comply with these terms. 